\title{
Conceitos básicos sobre segurança em trabalhos de campo para cursos de graduação em Geologia e Engenharia Geológica
}

\author{
Basic Concepts of FieldWork safety for undergraduate courses of GEOLOGy and Geological Engineering \\ Luiz Guilherme Poggio Teixeira ${ }^{1}$, Ana Elisa Silva de Abreu ${ }^{2}$ \\ 1 - GEólogo consultor, SP, BRASIL. - pogeologia@gmail.com \\ 2 - Depto. Geol. Rec. Naturals, Inst. Geoc. Unicamp, Campinas, SP, Brasil. - anaelisa@ige.unicamp.br
}

ABSTRACT: Throughout undergraduate courses of Geology and Geological Engineering Manuscrito: in Brazil, students will expend $20 \%$ of their time on fieldwork. As the risks on fieldwork are different from those found in classrooms and laboratories, they should be well evaluated; control measures should be implemented. This paper presents basic safety concepts and the main risks identified on field activities. It also proposes the establishment of a safety plan as an integral part of a code for undergraduate fieldwork activity. The plan should contain specific guidelines, appropriate documentation, and a training program. In order to be successful all parts involved must show their commitment, especially at the higher levels of decision making.

\author{
Recebido: 07/09/2017 \\ Corrigido: 28/11/2017 \\ Aceito: 11/12/2017
}

Citation: Teixeira L.G.P, Abreu A.E.S. 2017. Conceitos básicos sobre segurança em trabalhos de campo para cursos de graduação em Geologia e Engenharia Geológica.Terræ Didatica, 13(3):323-331. $<$ http://www.ige.unicamp.br/terraedidatica/>

Keywords: Safety plan, risk, hazard.

\section{Introdução}

As atividades de campo são centrais no processo de formação do aluno de graduação nos cursos de Geologia e Engenharia Geológica. Segundo a recente Diretriz Curricular do Ministério da Educação para estes cursos a carga horária mínima de atividades de campo é de 720 horas (Brasil 2015). Ou seja, alunos, professores e demais participantes de atividades de campo estarão submetidos a condições diferentes daquelas encontradas nas salas de aula por pelo menos um quinto do tempo do curso todo. Trata-se de um período considerável e a segurança durante a execução destas atividades não pode ser negligenciada. Apesar disso, no Brasil ainda são poucos os cursos que efetivamente se organizaram em torno desta questão.

Nos países desenvolvidos o contato das pessoas com a prevenção de acidentes se dá ainda na infância. Nas instituições de ensino dessas nações as crianças são educadas e treinadas a responder de forma rápida e coordenada a situações de risco como terremotos, tsunamis, avalanches de neve e tornados. A prevenção não se dá apenas em função de possíveis desastres naturais (muitas vezes restritos a determinadas áreas geográficas), mas também por causa de outros eventos mais comuns que podem ocorrer em qualquer lugar como incêndios, atropelamentos, enchentes e outros.
No Brasil a prevenção de acidentes (que independam da natureza) é negligenciada pela maioria dos habitantes. Nos lares este não é, tradicionalmente, um tema debatido. A formação escolar de base pouco ou nada contribui para despertar o interesse das crianças pela prevenção de acidentes. Muitas vezes o primeiro contato do cidadão brasileiro com esta questão se dará somente na fase adulta, quando ingressar no mercado de trabalho e mesmo assim dependendo do setor de atividade e da empresa (SENAI/CST 1999).

Diante deste quadro cultural, não surpreende que a prevenção de acidentes em atividades de campo em cursos superiores no Brasil seja assunto marginal ou mesmo desconsiderado.

Nos últimos anos, em função de eventos trágicos que ocorreram no passado recente uma luz acendeu-se sobre este tema. Dois eventos em particular, amplamente noticiados pela imprensa nacional e disseminados no meio acadêmico, se destacam. Em julho de 2006 um estudante do primeiro ano do curso de graduação de Geologia da Universidade Federal do Rio Grande do Norte (UFRN) faleceu durante a realização de um trabalho de campo no Pico do Cabugi, vítima de um impacto na cabeça (Tribuna do Norte 2006). Em 2013 o corpo de um aluno do curso de graduação de Geologia da Universidade Federal do Pará (UFPA) 
foi encontrado depois de três dias após ele ter desaparecido durante a realização de trabalhos de campo no norte do estado do Tocantins (G1 2013).

Como resultado do primeiro evento trágico descrito acima, a reitoria da UFRN criou formalmente normas de segurança em atividades acadêmicas de campo externas ao ambiente dos campi (SBG-RN 2011). Mais recentemente outros cursos de geologia criaram ou reviram seus protocolos de atividades de campo, enfatizando os aspectos relacionados à prevenção de acidentes. Dentre estes cursos podem ser citados os da Universidade de São Paulo (USP), Universidade Federal do Paraná (UFPR) e Universidade Federal do Ceará (UFC) (Departamento de Geologia-UFPR 2015, IGc-USP 2015, Departamento de Geologia-UFC sem data).

Deve-se destacar também o recente trabalho de Mansur et al. (2017), que abordou brevemente as questões de segurança em trabalhos de campo na área de geologia como item importante dentro de um código de conduta para trabalhos de campo.

Estas são medidas importantes, mas que ainda carecem de aprofundamento técnico. O presente trabalho procura ir além das abordagens iniciais tendo como base a experiência pessoal dos autores em segurança em atividades de campo, além de conceitos teóricos amplamente difundidos sobre prevenção de acidentes e a legislação vigente.

\section{Histórico da legislação}

A origem da prevenção de acidentes como conhecemos hoje surgiu na indústria. As primeiras ações nesse campo começaram na Inglaterra, berço da Revolução Industrial. Inicialmente a prevenção de acidentes era interpretada como sinal de fraqueza humana e, erroneamente, admirava-se o trabalhador que se arriscava na execução de qualquer tarefa (Gomes 2008). Foi somente no final do século XVIII que a questão da prevenção de acidentes e da saúde do trabalhador inglês ganhou repercussão. A primeira lei inglesa que adotou medidas de segurança de caráter preventivo foi aprovada pelo Parlamento em 1802 (UK Parliament, sem data).

O processo de industrialização difundiu-se rapidamente pela Europa e as medidas de prevenção de acidentes vinham logo atrás. Na América, onde o desenvolvimento da indústria ocorreu posteriormente, o primeiro ato governamental sobre prevenção de acidentes na indústria surgiu em 1877 (Gomes 2008) no estado de Massachusets.
No Brasil, o primeiro regulamento prevencionista surgiu no setor ferroviário em 1919 (ABPA 1995 apud Gomes 2008), mas a primeira legislação ampla no que se refere à prevenção de acidentes foi criada em 1934, por meio do Decreto 24.637 de 10 de abril de 1934. Menos de uma década depois foi publicada a Consolidação das Leis Trabalhistas (CLT). A CLT tornou-se um marco na legislação trabalhista brasileira, reunindo em um único documento não só as legislações relativas ao direito do trabalho, mas também os aspectos relacionados à saúde e segurança para os trabalhadores de todos os ramos de atividade.

O processo de industrialização evoluiu rapidamente no país na segunda metade do século XX, mas a prevenção de acidentes não a acompanhou da mesma maneira. No início da década de 1970 o Brasil foi considerado o "campeão mundial de acidentes de trabalho" (Soares 2008). Até aquele momento, entretanto, a legislação brasileira era basicamente corretiva e não preventiva. A preocupação maior recaía na determinação das indenizações por acidentes de trabalho, não na prevenção das causas dos acidentes (Camisassa 2015).

A década de 1970 foi marcante para mudar esta postura e em 1978 o Ministério do Trabalho regulamentou a Lei $6.514 / 1977$, aprovando as Normas Regulamentadoras (NR) de "Segurança e Medicina no Trabalho". Este é um marco na prevenção de acidentes no Brasil, sendo ampliadas desde então. Algumas das normas possuem caráter genérico e outras são mais específicas para determinados setores ou atividades. Entretanto, do ponto de vista legal elas são aplicáveis somente às empresas privadas e públicas e aos órgãos públicos que possuem empregados contratados pela CLT. Os requisitos de segurança referentes a servidores públicos municipais, estaduais ou federais constam (ou deveriam constar) em estatutos específicos (Camisassa 2015).

Como se pode ver, no Brasil existem legislações diferentes para distintas classes de profissionais no tocante à prevenção de acidentes. O quadro torna-se mais complexo para as instituições de ensino nacionais, pois, do ponto de vista legal, os alunos não se enquadram nas categorias descritas acima e, para completar, não existe legislação específica para segurança de atividades de campo. De qualquer forma os profissionais das instituições de ensino (em especial o corpo docente) envolvidos em trabalhos de campo podem e devem se cercar de profissionais da área do direito (advogados principalmente) e da 
segurança do trabalho (médicos, técnicos e engenheiros) para obter mais orientação.

\section{Definições e conceitos básicos}

Para o correto entendimento do tema, é necessário definir determinados conceitos e expressões. Primeiramente, a expressão "trabalho de campo" é definida, segundo a University Geoscience UK, como qualquer atividade desenvolvida por funcionários ou estudantes com o propósito didático, científico ou outras atividades enquanto representando a instituição fora do campus (USHA/UCEA 2011). No presente artigo o trabalho de campo será tratado como uma atividade prática e obrigatória de determinada disciplina (obrigatória ou optativa) ou de conjunto de disciplinas executada fora das salas de aula e dos laboratórios.

Obviamente, atividades de campo desenvolvidas em locais distantes do campus e com duração de vários dias (ou mesmo semanas) apresentam desafios maiores que aquelas atividades de campo desenvolvidas no interior do campus ou próximas a este. No entanto, ambas são atividades não ordinárias e possuem riscos distintos daqueles encontrados nos laboratórios, por exemplo.

Conforme explanado na Introdução, as NR e outras normas e regulamentos possuem aplicação legal somente para determinadas situações e determinados profissionais. Contudo, isto não quer dizer que os princípios e os fundamentos voltados à prevenção de acidentes contidos nesses documentos não possam ser utilizados em outras situações. Muitas das definições e dos conceitos empregados no presente texto têm como base este conjunto de normas nacionais, além de outras de caráter internacional.

A primeira importante diferenciação que se deve fazer é aquela entre risco e perigo. Embora seja comum usar o termo "perigo" como sinônimo de "risco" (conforme encontrado em muitos dicionários), formalmente no campo da segurança há diferenças entre eles. A definição de ambos é tratada aqui sob a ótica da OHSAS 18001/2007 (British Standard Institution 2007).

Perigo (do inglês "hazard") significa fonte, situação ou ato com potencial para causar danos à integridade física do ser humano, às instalações e/ ou equipamentos ou uma combinação deles. Por outro lado risco (do inglês "risk") é a probabilidade de ocorrência de determinada situação ou evento potencialmente perigoso à integridade física do ser humano, às instalações e/ou equipamentos em decorrência da efetiva exposição ao perigo. $\mathrm{O}$ risco pode ser reduzido até um nível que possa ser tolerado. Neste caso define-se "risco aceitável". Por último, o termo "dano" é empregado no presente texto como o resultado da exposição ao perigo.

Em poucas palavras o perigo é a fonte geradora e o risco é a exposição a esta fonte. Para ilustrar o caso tome-se como exemplo um motorista que não possui habilitação para conduzir um ônibus. Ele representa o perigo (a fonte geradora) e o risco neste caso é a possibilidade de acidentes com danos pessoais e materiais.

É importante definir também o que é ação preventiva e ação corretiva. A primeira define-se como ato que visa eliminar a causa de uma potencial situação indesejável (ou seja, elas buscam prevenir ocorrências). A segunda diz respeito ao ato que visa eliminar a causa de uma situação indesejável (ou seja, elas buscam evitar recorrências).

\section{Riscos ambientais e seus agentes}

Praticamente todo ambiente de trabalho possui um ou mais fatores que poderão causar danos à saúde. Os fatores são conhecidos como riscos ambientais (SENAI/CST 1999). A Norma Reguladora $\mathrm{n}^{\mathrm{o}} 9$ do Ministério do Trabalho, que regulamenta o programa de prevenção de riscos ambientais (PPRA), trata em detalhes destes riscos e seus agentes. Embora ela não seja voltada à prática de trabalhos de campo é importante usar os conceitos ali presentes como ponto de partida e adaptá-los ao problema em questão.

Os riscos ambientais podem ser entendidos como o conjunto das características intrínsecas do meio onde se desenvolve o trabalho de campo que podem acarretar em prejuízos à saúde e à integridade física dos envolvidos. Estes riscos podem ser causados por agentes que se dividem em cinco grupos: físicos, químicos, biológicos, ergonômicos e de acidentes, resumidos na Figura 1 e detalhados a seguir.

Agentes físicos - são representados pelas condições físicas presentes no ambiente, como a temperatura, a pressão, a umidade e, em menor proporção, por formas de energia como ruídos, vibrações e radiações. Como os trabalhos de campo se desenvolvem ao ar livre aqueles que participam dele estão sujeitos às intempéries, suas variações e suas consequências. Estes também são considerados agentes físicos. 
AGENTES CAUSADORES DE RISCOS AMBIENTAIS

\begin{tabular}{|l|l|}
\hline FisıCOS & temperaturas extremas, pressões anormais, ruídos, vibrações, radiações \\
\hline QUIMICOS & $\begin{array}{l}\text { substâncias, produtos ou compostos que podem penetrar no organismo através de } \\
\text { inalação, ingestão ou contato dermal. }\end{array}$ \\
\hline BIOLÓGICOS & $\begin{array}{l}\text { microrganismos patogênicos, animais peçonhentos, vegetais urticantes, } \\
\text { frutos venenosos, animais silvestres }\end{array}$ \\
\hline \hline ERGONÔMICOS & $\begin{array}{l}\text { posições incômodas, trabalhos fisicos pesados,repetitividade, } \\
\text { jornadas prolongadas, ritmo excessivo, monotonia }\end{array}$ \\
\hline \hline MECÂNICOS & $\begin{array}{l}\text { máquinas/equipamentos/ferramentas, defeituosas ou inadequadas, } \\
\text { armazenamento ou transporte de materiais, peças e equipamentos inadequado, } \\
\text { ausência e/ou deficiência de sinalização e/ou iluminação }\end{array}$ \\
\hline
\end{tabular}

Figura 1. Agentes ambientais

Agentes químicos - são as substâncias, produtos ou compostos químicos que podem penetrar no organismo humano por meio da inalação (pela via respiratória, nas formas de poeiras, fumos, névoas, neblinas, gases ou vapores), ingestão ou contato dermal. Aqui deve ser observada a forma como o agente químico se apresenta. O pó proveniente da crisotila (mineral comum em serpentinitos), por exemplo, é causador de doenças pulmonares. Portanto, a crisotila é o agente químico que se apresenta na forma de poeira.

Agentes biológicos - para a NR-9 (Brasil 1978a) são bactérias, fungos, bacilos, parasitas, protozoários, vírus entre outros. No presente artigo adota-se uma visão mais ampla do conceito "agentes biológicos", definindo-o como todo e qualquer agente de origem biológica que possa causar risco à integridade física do ser humano. Portanto, estão aqui incluídos os microrganismos, os animais peçonhentos, os vegetais que causam irritação da pele, os frutos venenosos, os animais silvestres e domesticados de pequeno, médio e grande porte e muitos outros.

Agentes ergonômicos - embora a NR-9 não os considere (nem os agentes de acidentes, descrito a seguir) outros instrumentos legais de caráter nacional, como a NR-22 (Brasil 1978b) (Segurança e Saúde Ocupacional na Mineração) ou internacional: OHSAS 18001/2007 (British Standard Institution 2007) e BS 8800 (British Standard Institution 1996) consideram os agentes ergonômicos. $\mathrm{E}$ em função da sua importância em trabalhos de campo eles são aqui descritos. Este grupo pode ser definido como os agentes caracterizados pela falta de adaptação das condições de trabalho às características psicofisiológicas do indivíduo. Aqueles que participam de trabalhos de campo se deparam com trabalhos físicos pesados, posições incômodas, repetitividade, jornadas prolongadas, ritmo excessivo e em alguns casos monotonia. Em geral esses agentes podem provocar desconforto, cansaço, dores musculares, fraqueza e sono entre outros.

Agentes de acidentes (ou mecânicos) - são arranjos físicos inadequados ou deficientes, máquinas/ equipamentos/ferramentas defeituosas ou inadequadas, armazenamento ou transporte de materiais, peças e equipamentos inadequado, ausência ou deficiência de sinalização e/ou iluminação, edificações defeituosas e outros. Há vários exemplos de agentes de acidentes em trabalhos de campo como a deficiência de iluminação em cavidades naturais, desmoronamentos de blocos, queda de altura, entre outros.

Apenas a presença de determinado agente não é suficiente para existir risco. Deve-se considerar, em conjunto, a sua natureza, concentração (para o caso de agentes químicos) ou intensidade (para os demais agentes) e tempo de exposição. Por exemplo, visitas técnicas em frentes de lavras de minas de urânio podem expor os alunos à radiação (o agente, neste caso). No entanto, se a intensidade da radiação for baixa e o tempo de exposição for pequeno, o risco é desprezível.

\section{Medidas de controle}

Os riscos ambientais devem ser avaliados de forma qualitativa (identificação de riscos potenciais e reconhecimento de riscos presentes) e quantitativa (mensurar a intensidade ou a concentração do risco). Após a identificação e mensuração dos mesmos, devem ser implantadas as medidas de controle. Medidas de controle são as ações tomadas com o objetivo de eliminar, minimizar ou controlar os riscos ambientais (Camisassa 2015).

As medidas de controle de caráter coletivo devem ser priorizadas. Não havendo esta possibilidade passa-se então à adoção de medidas administrativas ou de organização do trabalho $e$ apenas em último caso adotam-se equipamentos de proteção individual (EPI), como ilustrado na figura 2.

Segundo a NR-9 as medidas de caráter coletivo devem obedecer a seguinte hierarquia:

(a)Medidas que eliminam ou reduzam a utilização ou a formação de agentes prejudiciais à saúde; 
(b)Medidas que previnam a liberação ou disseminação desses agentes no ambiente de trabalho;

(c)Medidas que reduzam os níveis ou a concentração desses agentes no ambiente de trabalho.

Camisassa (2015) subdivide as medidas em dois grupos: medidas de controle na fonte geradora (item 'a') e medidas de controle no meio ou trajetória (itens 'b' e 'c').

Caso a implantação das medidas de caráter coletivo seja tecnicamente inviável ou se as medidas forem insuficientes ou encontram-se em fase de estudo, planejamento ou implantação, ou ainda em caráter complementar ou emergencial, deverão ser adotadas medidas de ordem geral (medidas de caráter administrativo ou de organização do trabalho).

Para ilustrar o caso toma-se como exemplo uma rodovia onde o risco de atropelamento é constante. A construção de uma passarela para pedestres é medida de engenharia que elimina por completo o risco. Por outro lado, se a construção de uma passarela não se justifica, a implantação de faixas de pedestres e a redução da velocidade dos veículos por meio de placas sinalizadoras é uma medida de ordem geral que reduz o risco a níveis aceitáveis.

$\mathrm{Na}$ impossibilidade de adoção das classes de medidas citadas acima, os equipamentos de proteção individual deverão ser empregados. Sendo assim, conforme já exposto anteriormente, o EPI deve ser a última alternativa, pois eles podem evitar ou reduzir uma eventual lesão, mas nunca eliminarão ou neutralizarão o risco.

Segundo redação da NR-6 (Brasil 1978c), que trata especificamente de equipamentos de proteção individual, EPI é todo o dispositivo ou produto, de uso individual utilizado pelo trabalhador, destinado à proteção de riscos suscetíveis de ameaçar a segurança e a saúde no trabalho.

Até recentemente a recomendação do EPI era responsabilidade da CIPA (Comissão Interna de Prevenção de Acidentes), conforme exposto pela NR-6. No entanto, desde 2010 essa comissão passou a desempenhar papel meramente opinativo sobre o tema, sendo que uma comissão específica ou um profissional tecnicamente habilitado deverá indicar o EPI apropriado para determinada tarefa (Camisassa 2015).

Deve-se destacar que, do ponto de vista da legislação trabalhista, não são considerados EPI

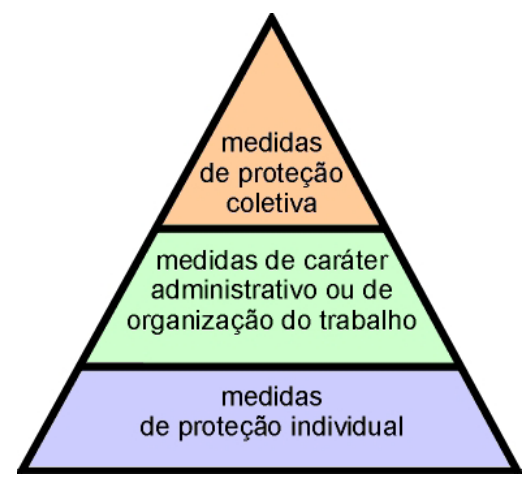

Figura 2. Modelo hierárquico de prioridades de medidas de controle

o protetor solar (produto que oferece proteção contra a incidência de radiação ultravioleta UVA e UVB), repelente de insetos, colete refletivo, chapéu e outros. No entanto, como estes acessórios contribuem para a segurança e para o conforto dos indivíduos que participam de trabalhos de campo eles devem ser recomendados pelos responsáveis.

\section{Riscos mais comuns em trabalhos de campo}

Como em qualquer atividade humana, há riscos que são sempre mais frequentes em cada tarefa. Sendo assim, existem riscos que são mais comuns em atividades de campo. Os riscos listados abaixo têm como base a experiência de campo dos autores, informações verbalmente fornecidas por outros docentes e profissionais da área de geologia e documentação internacional, notadamente da Universidade de Londres (Department of Earth and Planetary Sciences 2015) e da Universidade de Durham (Department of Earth Sciences 2016) e são identificados por estes autores como os mais frequentes em trabalhos de campo de geologia.

Queda de blocos-este é possivelmente o risco mais comum e mais conhecido em trabalhos de campo. Exposição de rochas e solos de alteração em encostas, taludes de corte em rodovias, minas a céu aberto e outros podem ser pontos de interesse geológico. No entanto, dependendo de alguns aspectos locais (como altura e declividade), estes pontos podem vir a oferecer riscos aos profissionais e estudantes.

Altura - trabalhos de campo próximos de escarpas e no topo de penhascos podem levar à queda de pessoas e/ou objetos. Espaços restritos e grande quantidade de indivíduos nestes locais podem potencializar o perigo. Deve-se avaliar também a presença de outras pessoas situadas abaixo que podem estar em risco. 
Acidentes envolvendo veículos - muitas atividades de campo envolvem a presença de veículos, seja para transportar os membros do grupo aos locais de interesse, seja pela passagem destes nas proximidades de onde o grupo se encontra. Há diversos cortes de estrada de elevado valor geológico e próximos a eles veículos passam em altas velocidades. Também são comuns as caminhadas e observações de pontos de interesse por estradas vicinais não pavimentadas com tráfego local.

Riscos atmosféricos - por ser um país majoritariamente tropical, os climas que predominam no Brasil não são extremos. No entanto, exposições dos participantes de trabalhos de campo a sol e chuva intensos podem trazer riscos. A exposição prolongada ao sol pode causar malefícios ao organismo humano como desidratação, insolação, hipertermia, problemas de pele e outros. Em relação às chuvas, os riscos também são diversos e podem alterar as condições do meio, deixando o piso mais liso (favorecendo as quedas), elevando o nível dos rios ou promovendo corridas de massa em encostas. Neste item também estão incluídos os riscos de queda de raios, especialmente em áreas abertas.

Riscos provenientes da fauna e flora local - em determinadas regiões ocorrem animais peçonhentos e/ ou venenosos, plantas tóxicas e insetos cuja picada (ou o conjunto de picadas) pode representar risco. Acidentes com mordidas de cobra são mais comuns em regiões ermas, mas outros animais (como aranhas e escorpiões) habitam tanto áreas rurais como urbanas. Há casos onde o contato com um desses organismos pode ocasionar apenas uma irritação localizada na superfície da pele. Porém, em outras situações pode levar à morte. Incluem-se neste item também os riscos que envolvem animais domesticados e criados por terceiros.

Emprego de martelo - uma das principais ferramentas de campo dos geólogos é o martelo. $\mathrm{O}$ martelo é comumente utilizado para a coleta de amostras de mão de rochas. No entanto, o mesmo deve ser manuseado adequadamente, para não gerar riscos à integridade física dos participantes (lançamento de fragmentos pontiagudos nos olhos, por exemplo).

Minas subterrâneas e cavidades naturais - a ausência de luz e o desconhecimento do traçado subterrâneo são riscos que devem ser avaliados e mitigados. Atividades nestes ambientes só devem ocorrer se forem essenciais ao propósito (didático, pesquisa, etc.) e contarem com equipamentos e medidas de segurança específicas.
Violência - há diversas áreas espalhadas pelo país, notadamente próximas ou dentro de comunidades carentes em áreas urbanas, com elevados índices de violência e alto risco para indivíduos estranhos à comunidade. Neste item também devem ser enquadradas as propriedades privadas rurais, principalmente naquelas onde há disputa pela posse da terra.

\section{Implantação de plano de segurança}

Como visto acima a segurança no trabalho de campo envolve o conhecimento dos riscos e a implantação de medidas de controle para os mesmos. Para se chegar a este estágio é preciso criar um plano de segurança em trabalhos de campo. Em certos locais no exterior o plano de segurança é parte integrante do código de conduta de atividades de campo. Esta visão também é compartilhada por Mansur et al. (2017).

Propõe-se neste trabalho que o plano de segurança contenha diretrizes específicas, documentação apropriada e programa de treinamentos. Acima de tudo, deve haver total comprometimento das instâncias superiores para que o mesmo seja efetivamente implantado.

O plano de segurança deve possuir diretrizes oficiais e elementares para a execução de trabalhos de campo. É recomendável que a Universidade, por meio de uma resolução da reitoria (por exemplo), tenha diretrizes gerais e que cada unidade particularize suas necessidades por meio de diretrizes específicas.

As diretrizes específicas deverão listar os riscos ambientais mais comuns das atividades de campo (já discutidos acima), sendo estes avaliados de forma qualitativa e quantitativa. Por fim, medidas de controle deverão ser previamente propostas. Casos particulares podem ser avaliados individualmente e, mesmo diante de situações previamente não identificadas, os envolvidos nas atividades deverão estar aptos a lidar com a mesma (ver item "treinamento" mais abaixo).

A prevenção de acidentes em trabalhos de campo começa pelo bom planejamento da atividade e este também deve fazer parte do plano de segurança. Itens básicos devem ser previamente definidos e informados aos participantes como o local (ou locais) e a duração do trabalho de campo, a definição do roteiro padrão, pontos de parada, necessidades de autorizações (poder público, particulares, concessionárias etc.), tipo de veí- 
culo (ou veículos) que será empregado (veículos coletivos, veículos com tração em todas as rodas, etc.), pontos de apoio (hospitais, postos de saúde, delegacias de polícia, etc.), locais de pernoite (se for o caso), refeições (se ocorrerão em estabelecimentos apropriados ou será necessário levar alimento para o campo) e outros.

As diretrizes comporão um documento único onde constarão as normas e os procedimentos de segurança a serem seguidos, as responsabilidades e as obrigações dos participantes. Toda a documentação sobre trabalho de campo deve ser de amplo conhecimento da comunidade e de fácil acesso aos interessados. Aqueles que tomarão parte nos trabalhos deverão ter ciência das particularidades da atividade e, dessa maneira, se preparar para a mesma ou alertar os organizadores sobre limitações pessoais que eventualmente possam existir.

Além das diretrizes, documentos complementares como ficha individual de informações de saúde, declaração de ciência dos riscos do trabalho de campo e documentação de autorização para participação de alunos menores de idade (se for o caso) são fundamentais para a organização e a segurança da atividade.

Por fim, o plano de segurança deve ser constantemente revisto para se adaptar às mudanças legais e à execução de boas práticas de segurança. Mas por melhor que um plano de segurança seja ele só evitará acidentes se todos os participantes das atividades de campo estiverem comprometidos em aplicá-lo corretamente.

\section{Treinamentos}

Não se pode exigir, por exemplo, de um aluno que ele leve um kit básico de primeiros socorros se ele não souber o que fazer com isso. Por outro lado, é praticamente inviável possuir um médico ou enfermeiro em cada grupo de alunos ou em cada atividade de campo, assim como também é inviável possuir um técnico ou engenheiro de segurança em cada uma dessas atividades.

Portanto, faz-se necessário lançar mão de cursos e palestras que orientem os envolvidos nos trabalhos de campo para que eles obtenham o mínimo de conhecimento sobre prevenção de acidentes e como lidar com acidentes que por ventura venham a ocorrer. Em última análise todos os indivíduos são responsáveis pela segurança própria e pela segurança coletiva. E para que isso ocorra todos devem estar devidamente preparados.

Na Tabela 1 é apresentada uma proposta de treinamentos e palestras voltados à segurança e prevenção de acidentes. Muitas vezes os recursos humanos para tais treinamentos já existem nos campus, por exemplo, técnicos de segurança, agentes da área de saúde, especialistas em animais peçonhentos ou vetores de doenças, etc. Mesmo que não existam, outras categorias profissionais do Estado como policiais florestais ou bombeiros podem contribuir com recursos humanos para a realização dos treinamentos.

Durante a vida profissional o geólogo estará sujeito a inúmeros outros riscos durante trabalhos de campo, por exemplo, na investigação de áreas

Tabela 1. Proposta de treinamentos e palestras voltados à segurança e prevenção de acidentes em trabalhos de campo

\begin{tabular}{l|l}
\hline Módulo & Proposta de ementa \\
\hline $\begin{array}{l}\text { Riscos ambientais em traba- } \\
\text { lhos de campo }\end{array}$ & $\begin{array}{l}\text { Abordagem das definições e dos conceitos básicos sobre riscos ambientais e seus } \\
\text { agentes. Apresentação dos riscos ambientais mais comuns em atividades de cam- } \\
\text { po e discussão das medidas de controle comumente adotadas. }\end{array}$ \\
\hline $\begin{array}{l}\text { Equipamentos de Proteção } \\
\text { Individual }\end{array}$ & $\begin{array}{l}\text { O que são, para que servem e como são utilizados. Quais os EPI mais utilizados } \\
\text { em trabalhos de campo e quando utilizá-los. }\end{array}$ \\
\hline $\begin{array}{l}\text { Animais peçonhentos e/ou } \\
\text { venenosos e plantas tóxicas }\end{array}$ & $\begin{array}{l}\text { Tipos e riscos que eles proporcionam. Distribuição geográfica dos mesmos. } \\
\text { Identificação e métodos de prevenção. Medidas gerais de emergência. }\end{array}$ \\
\hline $\begin{array}{l}\text { Noções básicas sobre primei- } \\
\text { ros socorros }\end{array}$ & $\begin{array}{l}\text { Identificação de sinais vitais e suas possíveis irregularidades. Abordagem e movi- } \\
\text { mentação da vítima. Aplicação de técnicas e procedimentos básicos para reesta- } \\
\text { belecer os sinais vitais. Imobilização de membros. }\end{array}$ \\
\hline Técnicas de resgate & $\begin{array}{l}\text { O que são, para que servem e quando devem ser executadas. Tipos de manobras } \\
\text { de resgate em locais de difícil acesso. Planejamento do resgate e equipamentos } \\
\text { utilizados. Progressão. }\end{array}$ \\
\hline Orientação e navegação & $\begin{array}{l}\text { Uso de carta topográfica e bússola. Estimativa da posição a partir de elementos } \\
\text { naturais. Técnicas de navegação sem emprego de dispositivos de geolocalização. }\end{array}$ \\
\hline
\end{tabular}


contaminadas. Entretanto, os trabalhos de campo do curso de graduação devem ser planejados de forma a minimizar riscos. Assim, na disciplina de hidrogeologia é possível ensinar as técnicas de amostragem de água subterrânea, porém, estes trabalhos de campo não devem ser realizados em áreas contaminadas, mas em áreas isentas de contaminação, apenas para treinamento das técnicas.

A prevenção de acidentes é algo que deve ser constantemente reforçado. Para tanto, propõem-se não só os treinamentos introdutórios, mas também os de reciclagem de conhecimentos. Um bom momento para transmitir estes conhecimentos é o período anterior ao início do ano letivo, principalmente para os alunos que recém ingressam à universidade. Um período não superior a uma semana de treinamento, com módulos de meio período a um período por tema, já será suficiente e extremamente abrangente. Há também a possibilidade de se criar treinamentos de reciclagem por meio de ferramentas "on line" na intranet de cada instituição.

Por último, somente com o total comprometimento da alta gerência os programas de prevenção de acidentes em trabalhos de campo podem ser efetivamente implementados. Por experiência dos autores, são inúmeros os exemplos de programas (dos mais diversos espectros) que foram implantados e, por total descompromisso das pessoas que ocupavam a hierarquia mais alta, fracassaram.

\section{Conclusão}

Os riscos envolvidos em trabalhos de campo possuem diversas particularidades e divergem muito daqueles existentes em salas de aula e laboratórios. Portanto, devem ser tratados de forma particular.

No presente artigo foram identificados, com base na experiência dos autores e em revisão bibliográfica, oito principais riscos neste tipo de atividade, a saber: queda de blocos; trabalhos em alturas; acidentes envolvendo veículos; riscos atmosféricos; riscos provenientes da fauna e da flora; emprego de martelo; minas subterrâneas e cavidades naturais e violência. Os riscos devem ser devidamente avaliados de forma qualitativa e quantitativa para que, em seguida, sejam implantadas as medidas de controle com o objetivo de eliminá-los, minimizá-los ou controlá-los.

O plano de segurança é o documento que consolida as ações que envolvem a segurança na instituição e deve conter diretrizes específicas, documentação apropriada e programa de treinamentos. Para que as ações visando a segurança em trabalhos de campo sejam bem sucedidas é indispensável o total comprometimento das instâncias superiores com a sua implantação. Quanto a treinamentos, sugerem-se treinamentos introdutórios e treinamentos de reciclagem de conhecimentos, que englobem pelo menos os seguintes aspectos: riscos ambientais em trabalhos de campo, equipamentos de proteção individual, animais peçonhentos e/ou venenosos e plantas tóxicas, noções básicas sobre primeiros socorros, técnicas de resgate, orientação e navegação.

Tratando o assunto com a importância que merece, as instituições de ensino colaborarão não apenas para o aumento da segurança dos funcionários, colaboradores e alunos, mas também para a formação profissional do corpo discente. No mercado de trabalho a exigência em relação à segurança é cada vez maior; as empresas dispendem quantias expressivas na formação e conscientização dos funcionários. Treinar alunos para prevenção de acidentes em trabalhos de campo é, também, prepará-los para o competitivo mercado de trabalho, pois as melhores empresas valorizam aqueles funcionários (ou postulantes às vagas) que zelam pela segurança.

\section{Referências}

Brasil. Secretaria de Segurança e Saúde no Trabalho do Ministério do Trabalho. 1978a. Norma Regulamentadora $n .9$ - Programa de prevenção de riscos ambientais. Portaria GM n. 3.214, de 8 de junho de 1978. URL: <http://trabalho.gov.br/images/Documentos/SST/ NR/NR09/NR-09-2016.pdf>. Acesso 2.12. 2016.

Brasil Secretaria de Segurança e Saúde no Trabalho do Ministério do Trabalho. 1978b. Norma Regulamentadora n. 22 - Segurança e saúde ocupacional na mineração. Portaria GM n. 3.214, de 8 de junho de 1978. URL: < http://trabalho.gov.br/images//Documentos/SST/NR/NR-22-atualizada-2016.pdf > . Acesso 2.08.2016.

Brasil Secretaria de Segurança e Saúde no Trabalho do Ministério do Trabalho. 1978c. Norma Regulamentadora n. 6 -Equipamento de Proteção Individual (EPI). Portaria GM n. 3.214, de 8 de junho de 1978. URL: <http://trabalho.gov.br/images/Documentos/SST/ NR/NR6.pdf > . Acesso 2.12. 2016.

Brasil Câmara de Educação Superior/Conselho Nacional de Educação/Ministério da Educação. 2015. Institui as diretrizes curriculares nacionais para os cursos de graduação na área de geologia, abrangendo os cursos de bacharelado em Geologia e em Engenharia Geológica e dá outras providências. Resolução n.1, de 6 jan. 2015. URL: $<$ http://portal.mec.gov.br/index.php?option $=$ com docman\&view $=$ download $\&$ alias $=16871$-res-cneces-001-06012015\&category_slug=janeiro-2015- 
pdf\&Itemid =30192> . Acesso 2.08.2016.

British Standard Institution 1996. Guide to Occupational health and safety management systems. BS 8800 . Londres. $46 \mathrm{p}$.

British Standard Institution 2007. Occupational Health and Safety Assessment Series. OHSAS 18001. Londres,. 23p. (Trad. para português). URL: <http:// comum.rcaap.pt/bitstream/10400.26/7319/2/Anexo\%20I\%20OHSAS180012007_pt.pdf $>$. Acesso 2.08.2016.

Camisassa M. 2015. Segurança e Saúde no Trabalho - NRs 1 a 36 Comentadas e Descomplicadas. Editora Método Ltda. São Paulo, 909p.

Departamento de Geologia-UFPR 2015. Complemento ao Caderno de Normas que regulamentam a Resolução do Conselho Setorial do Setor de Ciências da Terra Sobre Aulas de Campo e Atividades Correlatas. Setor de Ciências da Terra (SCT), Universidade Federal do Paraná. Curitiba, 2015. URL: < http://www.geologia.ufpr. br/seguranca2015.pdf>. Acesso 30.11. 2016.

Departamento De Geologia-UFC 2016. Normas e procedimentos de segurança em trabalhos de campo. Universidade Federal do Ceará. Fortaleza, 2016. URL: < http:// www.geologia.ufc.br/graduacao/248-normas-e-procedimentos-de-seguranca-em-trabalhos-de-campo >. Acesso 20.11. 2016.

Department of Earth and Planetary Sciences 2015. Fieldwork Safety Code of Practice. Birkbeck College, Univ. London. URL: < http:/www.bbk.ac.uk/geology/downloads/fieldsafetyguide.pdf>. Acesso 21.08.2017.

Department of Earth Sciences 2016. Health and Safety Handbook. Univ. Durham Earth Sciences Health and Safety Policy. Year 2016-17 URL: < https://www. dur.ac.uk/resources/earth.sciences/Earth_Sciences_Health_Safety_Handbook_161.pdf > . Acesso 21.08.2017.

G1 2013. Universitário do Pará que sumiu no Tocantins é encontrado morto. Palmas, 28 ago. 2013. URL: <http:/g1.globo.com/to/tocantins/noticia/2013/08/ universitariodoparaquesumiunotocantinseencontradomorto.html>. Acesso 30.11.2016.

Gomes, C. A. 2008 Mudanças Organizacionais no processo de implantação da OHSAS 18.001 no sistema de gestão integrado e sua interface com a sustentabilidade: um estudo de caso. Fac. Tecnol., Univ. Fed. Amazonas. 103p. (Dissert. Mestr.).
IGc-USP 2015. Protocolo de Conduta e Segurança em Aulas de Campo. Inst. Geoc. USP. URL: < http://www. igc.usp.br/uploads/media/Protocolo_de_seguranca_ no_campo_IGc_USP_01.pdf > . Acesso 30.11.2016.

Mansur K.L., Ponciano C.M.O., Castro A.R.S.F. 2017. Contributions to a Brazilian Code of Conduct for Fieldwork in Geology: an approach based on Geoconservation and Geoethics. An. Acad. Bras. Ciênc., (2017) 89(1, Suppl.). URL: < http://www.scielo.br/ pdf/aabc/v89n1s0/0001-3765-aabc-201720170002. pdf > . Acesso 21.08.2017.

SENAI/CST 1999. Procedimento e Higiene do Trabalho Instrumentação. Programa de Certificação de Pessoal de Manutenção. Espírito Santo. 126 p.

Soares L.J.P. 2008. Os impactos financeiros dos acidentes do trabalho no orçamento brasileiro: uma alternativa política e pedagógica para redução dos gastos. Monogr. Apres. ISC (Instituto Serzedello Corrêa) do Tribunal de Contas da União. Curso Espec. Orçamento Público. Tribunal de Contas da União/Câmara dos Deputados/Senado Federal. 67p.

Sociedade Brasileira de Geologia. SBG-RN 2011. Repasse de Informações sobre Problemas de Segurança nas Atividades de Campo dos departamentos de Geologia e Geofísica da UFRN. Resolução nº 162/2010-CONSEPE, de 13 de julho de 2010. URL: < http://ineditasolucoes.com.br/ig/novo2/wp-content/uploads/2015/05/ problemas-de-seguranca-nas-atividades-de-campo-departamento-de-geologia-ufrn.pdf $>$. Acesso 29.11.2016.

Tribuna do Norte 2006. Estudante morre no Pico do Cabugi. Natal, 9 jul. 2006. URL: < http://www.tribunadonorte.com.br/noticia/estudante-morre-no-pico-do-cabugi/15639>. Acesso 30.11. 2016.

UK Parliament. Sem Data. Reforming Society in the 19th Century - Early Factory Legislation. URL: < http:// www.parliament.uk/about/living-heritage/transformingsociety/livinglearning/19thcentury/overview/ earlyfactorylegislation/> . Acesso 11.07.2017.

Universities Safety and Health Association (USHA)/ Universities and Colleges Employers Association (UCEA) 2011. Guidance on Health and Safety in Fieldwork. URL: < https://www.geolsoc.org.uk/ /me$\mathrm{dia} /$ shared/documents/education $\% 20$ and $\% 20$ careers/UGUK/USHA\%20guidance\%20on \%20HS\%20 in\%20Fieldwork.pdf?la $=$ en $>$. Acesso 21.08.2017.

Resumo: Durante 0 curso de graduação os alunos dos cursos de Geologia e Engenharia Geológica no Brasil consumirão $20 \%$ do tempo em trabalhos de campo. Como os riscos nos trabalhos de campo são diferentes daqueles encontrados nas salas de aulas e nos laboratórios os mesmos devem ser avaliados e medidas de controle devem ser implantadas. No presente artigo são apresentados os conceitos básicos sobre segurança e identificados os principais riscos presentes nas atividades de campo de graduação. Em seguida propõe-se a criação de um plano de segurança como parte integrante de um código de atividades de campo. 0 plano deverá conter diretrizes específicas, documentação apropriada e programa de treinamentos. Para que o plano obtenha sucesso, ou seja, evite riscos, deverá haver engajamento por parte de todos os participantes da atividade e comprometimento das esferas superiores em relação à segurança.

Palavras-chaves: Plano de segurança, risco, perigo. 